\title{
青海省森林乔木层碳储量现状及固碳潜力
}

\author{
陈科宇 ${ }^{1}$ 字洪标 ${ }^{1}$ 阿的鲁骥 ${ }^{1}$ 胡 雷 $^{1}$ 王根绪 $^{2}$ 王长庭 $^{1^{*}}$
}

${ }^{1}$ 西南民族大学青藏高原研究院, 成都 $610041{ }^{2}$ 中国科学院成都山地灾害与环境研究所中国科学院山地表生过程与生态调控重点实验室, 成都 610041

摘 要 为阐明青海省森林生态系统乔木层植被碳储量现状及其分布特征, 该研究利用 240 个标准样地实测的乔木数据, 估 算出青海省森林生态系统不同林型处于不同龄级阶段的平均碳密度, 并结合青海省森林资源清查资料所提供的不同龄级的 各林型面积, 估算了青海省森林生态系统乔木层的固碳现状、速率和潜力。结果表明: 1) 2011年青海省森林乔木层平均碳密 度为76.54 Mg $\cdot \mathrm{hm}^{-2}$, 总碳储量为27.38 $\mathrm{Tg}$ 。云杉(Picea spp.)林、柏木(Cupressus funebris)林、桦木(Betula spp.)林、杨树(Populus spp.)林是青海地区的主要林型, 占青海省森林面积的 $96.23 \%$, 占青海省乔木层碳储量的 $86.67 \%$, 其中云杉林的碳储量(14.78 $\mathrm{Tg})$ 和碳密度 $\left(106.93 \mathrm{Mg} \cdot \mathrm{hm}^{-2}\right)$ 最高。按龄级划分, 乔木层碳储量表现为过熟林>中龄林>成熟林>近熟林>幼龄林。2)青海省乔 木层总碳储量从 2003 年的 $23.30 \mathrm{Tg}$ 增加到 2011 年的 $27.38 \mathrm{Tg}$, 年平均碳增量为 $0.51 \mathrm{Tg} \cdot \mathrm{a}^{-1}$ 。乔木层固碳速率为 $1.06 \mathrm{Mg} \cdot \mathrm{hm}{ }^{-2} \cdot \mathrm{a}^{-1}$, 其中柏木林的固碳速率最大 $\left(0.44 \mathrm{Mg} \cdot \mathrm{hm}^{-2} \cdot \mathrm{a}^{-1}\right)$; 桦木林的固碳速率为负值 $\left(-1.06 \mathrm{Mg} \cdot \mathrm{hm}^{-2} \cdot \mathrm{a}^{-1}\right)$ 。3) 青海省乔木层植被固碳潜力 为8.50 Tg, 其中云杉林固碳潜力最高 $(3.40 \mathrm{Tg})$ 。该研究结果表明青海省乔木层具有较大的固碳潜力, 若对现有森林资源进行 合理管理和利用, 将会增加青海省森林的碳固存能力。

关键词 碳储量; 固碳速率; 固碳潜力; 乔木层; 青海省

陈科宇, 字洪标, 阿的鲁䩀, 胡雷, 王根绪, 王长庭 (2018). 青海省森林乔木层碳储量现状及固碳潜力. 植物生态学报, 42, 831-840. DOI: $10.17521 /$ cjpe.2018.0058

\section{Current stocks and potential of carbon sequestration of the forest tree layer in Qinghai Prov- ince, China}

CHEN Ke-Yu ${ }^{1}$, ZI Hong-Biao ${ }^{1}$, ADE Luji ${ }^{1}, \mathrm{HU}_{\text {Lei }}{ }^{1}$, WANG Gen-Xu ${ }^{2}$, and WANG Chang-Ting ${ }^{{ }^{*}}$

${ }^{1}$ Institute of Qinghai-Tibetan Plateau, Southwest University for Nationalities, Chengdu 610041, China; and ${ }^{2}$ Key Laboratory of Mountain Surface Processes and Ecological Regulation of Chinese Academy of Sciences, Institute of Mountain Hazards and Environment, Chinese Academy of Sciences, Chengdu 610041, China

\section{Abstract}

Aims Our objective was to estimate the carbon storage in the forest tree layer in Qinghai Province, China.

Methods Based on forest resource inventory data and field investigation data, we estimated the carbon storage, sequestration rate and potentials in the forest tree layer in the Qinghai Province.

Important findings The carbon density and total carbon storage of forest tree layer in Qinghai Province was 76.54 Mg $\cdot \mathrm{hm}^{-2}$ and $27.38 \mathrm{Tg}$, respectively, of which four forest types (Picea spp. forest, Cupressus funebris forest, Betula spp. forest and Populus spp. forest) accounted for $86.67 \%$ while their areas were $96.23 \%$ of total forest areas in Qinghai. The carbon density and carbon storage of Picea spp. forest was $106.93 \mathrm{Mg} \cdot \mathrm{hm}^{-2}$ and $14.78 \mathrm{Tg}$, respectively, which was the largest among all forest types. The carbon storage of the forest tree layer at different stand ages followed the sequence of over-mature forest $>$ middle-aged forest $>$ mature forest $>$ near-mature forest $>$ young forest. In addition, the carbon storage of forest tree layer in the province increased from $23.30 \mathrm{Tg}$ in 2003 to $27.38 \mathrm{Tg}$ in 2011. The average annual growth of carbon and carbon sequestration rate were $0.51 \mathrm{Tg}$ and 1.06 $\mathrm{Mg} \cdot \mathrm{hm}^{-2} \cdot \mathrm{a}^{-1}$, respectively. The maximum and minimum of carbon sequestration rate were respectively found in Cupressus funebris forest $\left(0.44 \mathrm{Mg} \cdot \mathrm{hm}^{-2} \cdot \mathrm{a}^{-1}\right)$ and Betula spp. forest $\left(-1.06 \mathrm{Mg} \cdot \mathrm{hm}^{-2} \cdot \mathrm{a}^{-1}\right)$. The mean carbon sequestration potential reached $8.50 \mathrm{Tg}$ in 2011, with the highest value found in Picea spp. forest (3.40 Tg). These findings suggested high carbon sequestration potential of forest tree layer in Qinghai Province. Therefore, the carbon storage in Qinghai Province could be increased through better forest management and utilization.

收稿日期Received: 2018-03-13 接受日期Accepted: 2018-08-06

基金项目: 中国科学院战略性先导科技专项(XDA05050207)。Supported by the Strategic Priority Research Program of the Chinese Academy of Sciences (XDA05050207).

* 通信作者Corresponding author (wangct6@163.com, wangct@swun.edu.cn) 
Key words carbon storage; carbon sequestration rate; carbon sequestration potential; arbor; Qinghai Province

Chen KY, Zi HB, ADe LJ, Hu L, Wang GX, Wang CT (2018). Current stocks and potential of carbon sequestration of the forest tree layer in Qinghai Province, China. Chinese Journal of Plant Ecology, 42, 831-840. DOI: 10.17521/cjpe.2018.0058

碳循环是全球气候变化研究中备受国际社会关 注的一个核心问题(Schlesinger, 1977; Luan et al., 2011; Wani et al., 2014)。碳循环分为碳源和碳汇两 个过程, 碳源是指碳排放的源头, 碳汇是指碳的储 存和吸收。陆地圈与大气圈之间的碳循环被认为是 处于平衡状态, 但是经研究发现由人为活动所造成 部分 $\mathrm{CO}_{2}$ 去向不明, 这种情况被人们称为失汇现象 (方精云和郭兆迪, 2007)。针对全球“失汇”现象, 多 数学者认为这是对森林生态系统缺乏足够的了解所 致(Tans et al., 1990; 刘国华等, 2000; 王效科等, 2002), 因而对森林生态系统功能进行充分的研究 是必要的。

森林生态系统是陆地生物圈的主体, 由于其巨 大的碳库功能和较高的生产力, 在调节全球碳平 衡、减缓大气中 $\mathrm{CO}_{2}$ 等温室气体浓度上升以及维持 全球气候稳定等方面具有不可替代的作用(Kauppi et al., 1992; Dixon et al., 1994; Pan et al., 2011, 2013)。目前, 针对森林的植被碳储量和碳汇进行了 大量研究(Rice et al., 2004; Akseslsson et al., 2005; 杨洪晓等, 2005; 王秀云和孙玉军, 2008; 张玮辛等, 2012), 但多数研究集中在全球或国家尺度上(Dixon et al., 1994; 王效科等, 2001; Li et al., 2004; 赵敏和 周广胜, 2004)。目前不同研究得到的我国碳储量估 算值相差达到100多Pg (Tang et al., 2018)。因此需要 通过对不同省份、不同林型进行多组分详细的调查 分析, 来提升我国碳储量估算的精度。

乔木作为森林植被主体, 能够贡献森林生态系 统地上部分大部分的碳储量 $(81.37 \%-95.83 \%$ )(关晋 宏等, 2016; 黄晓琼等, 2016; 李银等, 2016; 王建等, 2016), 同时由于其生长周期长, 固碳速率相对稳定, 且不同乔木种间固碳速率和固碳潜力存在差异(孙 世群等, 2008), 所以目前大量研究关注于乔木层的 碳储量、固碳速率和固碳潜力。并将乔木层的碳储 量、固碳速率和固碳潜力作为森林生态系统功能发 挥程度的重要指标。青海省是青藏高原的重要组成 部分, 气候类型多样、地形地貌复杂, 同时青海省还 是长江、黄河、澜沧江的发源地, 被誉为“中华水 塔”。省内的森林生态系统承担着维持气候、生态环 境稳定和保水固碳的重要功能, 但其因地形环境等
因素, 省内森林生态系统各类基础信息数据相对不 全面, 且森林都不同程度受人为扰动影响。目前已 有一系列对于省内森林生态系统的研究, 多集中于 祁连山区范围内(陈文年等, 2003; 张鹏等, 2010), 也有研究通过青海省森林资源清查资料结合蓄积量生物量方程的方法估算了青海省碳储量情况(卢航 等, 2013; 胡雷等, 2015)。采用青海省森林资源清查 资料与实地调查数据相结合的方法来估算青海省内 乔木层固碳现状、速率和潜力的数据资料相对匮乏, 导致了对青海省乔木层碳汇功能了解不充分, 严重 影响了我们对其生态功能进行全面了解, 进而限制 了森林资源的合理利用。实地调查虽易受地形等因 素的影响, 限制调查区域, 但通过实地调查测量不 但能够得出相对更精确的数据结果 (Tang et al., 2018), 同时可以对已是多年前提出的生物量与蓄 积量回归方程, 特别是对于青海省内各类乔木碳储 量的估算进行实地验证(方精云和徐嵩龄, 1996; 罗 天祥等, 1998; Fang et al., 2001)。利用青海省森林资 源连续清查资料数据和标准样地实测数据相结合的 方法评估青海省森林生态系统乔木层的固碳现状、 速率和潜力, 可以为我国区域尺度上的森林碳汇估 算研究提供基础数据和科学参考。

\section{1 材料和方法}

\section{1 区域概况}

青海省位于青藏高原的东北部 $\left(31.65^{\circ}-39.32^{\circ}\right.$ $\mathrm{N}, 89.58^{\circ}-103.07^{\circ} \mathrm{E}$ ), 是长江、黄河、澜沧江的发源 地。燕山运动奠定其地形复杂多样, 高山、丘陵、 河谷、盆地交错分布, 最低海拔 $1650 \mathrm{~m}$, 最高海拔 $6860 \mathrm{~m}$, 平均海拔 $3500 \mathrm{~m}$ 以上, 属典型高原大陆 性气候。年平均气温-3.7-6.0 ${ }^{\circ} \mathrm{C}$, 年日照时间 2 340$3550 \mathrm{~h}$, 年降水量16.7-776.1 mm (大部分 $400 \mathrm{~mm}$ 以 下), 年蒸发量1 118.4-3 536.2 mm (董旭, 2009)。

根据青海省森林资源连续清查结果, 青海省土 地总面积7 $215.24 \times 10^{4} \mathrm{hm}^{2}$, 其中林地面积 $634.00 \times$ $10^{4} \mathrm{hm}^{2}$, 占 $8.79 \%$; 森林面积 $329.56 \times 10^{4} \mathrm{hm}^{2}$, 占林 地面积的 $51.98 \%$, 森林覆盖率 $4.57 \%$ 。森林植被分布 于 $96^{\circ} \mathrm{E}$ 以东, 主要江河及其支流的河谷两岸, 大多 分布在海拔2 500-4 $200 \mathrm{~m}$, 以寒温带常绿针叶林亚 
型为主, 其次为落叶林植被型(多为原始林破坏后 的次生类型)。植被地域上跨青藏高原、温带荒漠和 温带草原 3 个植被区, 具有高寒和旱生的特点, 常见 的针叶树种有云杉 (Picea spp.)、圆柏 (Sabina chinensis) 等, 阔叶树种有杨树(Populus spp.)、桦木 (Betula spp.)等(张永利等, 2007; 董旭, 2009)。

\section{2 采样点设置}

本次研究采用普遍调查与典型调查相结合的方 法来进行样地设置。依据青海省以往的森林清查资 料所提供的各林型面积和蓄积量等信息, 综合考虑 各个林型在全省森林中面积和蓄积量的不同权重, 并以此为标准, 兼顾做到调查的全面性、均匀性和 可行性, 来进行样地设置。共设置野外调查样地 80 个(图1), 每块样地设置3个重复样方, 共 240 个, 其 中云杉林样方 137 个, 桦木林样方 40 个, 圆柏林样方 36 个, 杨树林样方 24 个, 其他林型样方 3 个。

\section{3 调查方法}

每个样点设置 3 个重复样方 $(50 \mathrm{~m} \times 20 \mathrm{~m}$ 或 $30 \mathrm{~m}$ $\times 20 \mathrm{~m})$, 样点间距至少 $100 \mathrm{~m}$ 。调查指标包括: 地理
位置、海拔高度、坡度、坡向、树种组成、投影面 积、郁闭度、人为活动事件描述、人为活动影响程 度等。并对样地内胸径大于 $5 \mathrm{~cm}$ 的乔木全部进行每 木检尺, 测定树高和胸径。采集乔木层优势种各部 分器官鲜质量约 $300 \mathrm{~g}$ 样品带回实验室, 烘干, 采用 重铬酸钾-硫酸氧化法测定乔木树种各器官碳含量 (董鸣, 1997; 黄从德等, 2008)。

\section{4 数据处理}

\subsection{1 青海省乔木层固碳现状计算}

1.4.1.1 青海省不同林型乔木层碳密度计算 根据 实地样方中测量得到的乔木胸径 $(D)$ 和树高 $(H)$, 结 合表1中的异速生长方程, 计算样方中每株乔木的 器官生物量 $(\mathrm{kg})$, 并乘以相应器官含碳率, 后加和 得到单株乔木的碳储量 $(\mathrm{kg})$, 再累加样方内所有乔 木的碳储量, 得到样方内乔木层的总碳储量 $(\mathrm{Mg})$, 除以该样方面积得到乔木层碳密度 $\left(\mathrm{Mg} \cdot \mathrm{hm}^{-2}\right)$ 。将同 一林型且同一龄级(林龄划分标准见表2)的样方碳 密度进行归类求出平均值, 作为该林型在此龄级的 碳密度。

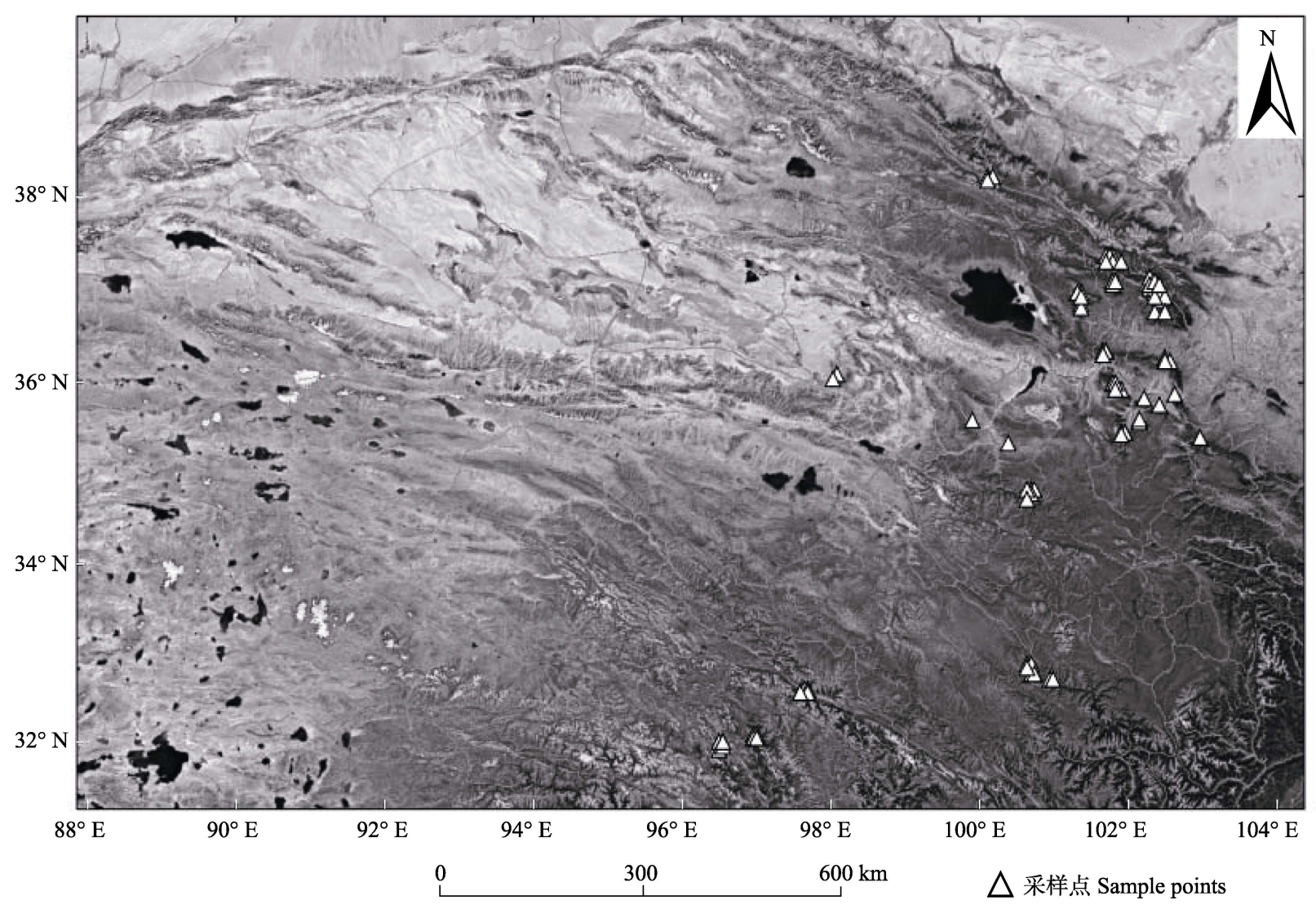

图1 青海省森林采样点分布图。

Fig. 1 Distribution of sampling sites in the forests in Qinghai Province. 
表1＼cjkstart青海省优势树种不同器官生物量异速生长方程

Table 1 Biomass equations for different organs (stem, branches, leaves, and roots) of dominant trees (groups) in Qinghai Province

\begin{tabular}{|c|c|c|c|c|}
\hline 森林类型 Forest type & 器官 Organ & 生物量方程 Biomass equation & $R^{2}$ & 胸径 Diameter at breast height $(\mathrm{cm})$ \\
\hline \multirow{4}{*}{$\begin{array}{l}\text { 云杉林 } \\
\text { Picea forest }\end{array}$} & 干 Stem & $W_{\mathrm{S}}=0.0447\left(D^{2} H\right)^{0.8564}$ & 0.986 & \multirow[t]{4}{*}{$1.0-88.0$} \\
\hline & 枝 Branch & $W_{\mathrm{B}}=0.0184\left(D^{2} H\right)^{0.8539}$ & 0.988 & \\
\hline & 叶 Leaf & $W_{\mathrm{L}}=0.012\left(D^{2} H\right)^{0.8654}$ & 0.992 & \\
\hline & 根 Root & $W_{\mathrm{R}}=0.0084\left(D^{2} H\right)^{0.9405}$ & 0.992 & \\
\hline \multirow{4}{*}{$\begin{array}{l}\text { 杨树林 } \\
\text { Populus forest }\end{array}$} & 干 Stem & $W_{\mathrm{S}}=0.0417\left(D^{2} H\right)^{0.866}$ & 0.992 & \multirow[t]{4}{*}{$7.2-21.0$} \\
\hline & 枝 Branch & $W_{\mathrm{B}}=0.0095\left(D^{2} H\right)^{0.8951}$ & 0.986 & \\
\hline & 叶 Leaf & $W_{\mathrm{L}}=0.0035\left(D^{2} H\right)^{0.8774}$ & 0.990 & \\
\hline & 根 Root & $W_{\mathrm{R}}=0.0289\left(D^{2} H\right)^{0.786}$ & 0.886 & \\
\hline \multirow{4}{*}{$\begin{array}{l}\text { 针叶混交林 } \\
\text { Mixed coniferous forest }\end{array}$} & 干 Stem & $W_{\mathrm{S}}=0.0373\left(D^{2} H\right)^{0.9758}$ & 0.784 & \multirow[t]{4}{*}{$3.0-178.5$} \\
\hline & 枝 Branch & $W_{\mathrm{B}}=0.0082\left(D^{2} H\right)^{1.08419}$ & 0.662 & \\
\hline & 叶 Leaf & $W_{\mathrm{L}}=0.0207\left(D^{2} H\right)^{0.8481}$ & 0.619 & \\
\hline & 根 Root & $W_{\mathrm{R}}=0.0379\left(D^{2} H\right)^{0.7321}$ & 0.542 & \\
\hline \multirow{4}{*}{$\begin{array}{l}\text { 阔叶混交林 } \\
\text { Mixed broad-leaved forest }\end{array}$} & 干 Stem & $W_{\mathrm{S}}=0.0401\left(D^{2} H\right)^{0.8514}$ & 0.933 & \multirow[t]{4}{*}{$1.4-67.5$} \\
\hline & 枝 Branch & $W_{\mathrm{B}}=0.0079\left(D^{2} H\right)^{1.007}$ & 0.901 & \\
\hline & 叶 Leaf & $W_{\mathrm{L}}=0.0075\left(D^{2} H\right)^{0.8592}$ & 0.846 & \\
\hline & 根 Root & $W_{\mathrm{R}}=0.0176\left(D^{2} H\right)^{0.8841}$ & 0.917 & \\
\hline \multirow{4}{*}{$\begin{array}{l}\text { 针阔混交林 } \\
\text { Mixed coniferous and broad-leaved forest }\end{array}$} & 干 Stem & $W_{\mathrm{S}}=0.0287\left(D^{2} H\right)^{0.9953}$ & 0.801 & \multirow[t]{4}{*}{$1.4-178.5$} \\
\hline & 枝 Branch & $W_{\mathrm{B}}=0.0067\left(D^{2} H\right)^{1.0999}$ & 0.696 & \\
\hline & 叶 Leaf & $W_{\mathrm{L}}=0.013\left(D^{2} H\right)^{0.8888}$ & 0.656 & \\
\hline & 根 Root & $W_{\mathrm{R}}=0.0299\left(D^{2} H\right)^{0.7547}$ & 0.609 & \\
\hline
\end{tabular}

引自生态系统固碳项目技术规范编写组 $(2015) 。 D$, 胸径 $(\mathrm{cm}) ; H$, 树高 $(\mathrm{m}) ; W_{\mathrm{S}}$, 树干生物量 $(\mathrm{kg}) ; W_{\mathrm{B}}$, 树枝生物量 $(\mathrm{kg}) ; W_{\mathrm{L}}$, 树叶生物量 $(\mathrm{kg}) ; W_{\mathrm{R}}$, 根生物 量 $(\mathrm{kg})$ 。

Based on the Technical Manual Writing Group of Ecosystem Carbon Sequestration Project (2015). $D$ and $H$ refer to tree diameter at breast height (cm) and tree height $(\mathrm{m})$, respectively. $W_{\mathrm{S}}, W_{\mathrm{B}}, W_{\mathrm{L}}$ and $W_{\mathrm{R}}$ refer to stem biomass $(\mathrm{kg})$, branch biomass $(\mathrm{kg})$, leaf biomass $(\mathrm{kg})$ and root biomass $(\mathrm{kg})$, respectively.

表2 青海省主要森林类型林龄组划分标准(a)

Table 2 Criteria of forest age group classification for major forest types in Qinghai Province (a)

\begin{tabular}{lccccc}
\hline $\begin{array}{l}\text { 林型 } \\
\text { Forest type }\end{array}$ & $\begin{array}{c}\text { 幼龄林 } \\
\text { Young forest }\end{array}$ & $\begin{array}{c}\text { 中齡林 } \\
\text { Middle-aged forest }\end{array}$ & $\begin{array}{c}\text { 近熟林 } \\
\text { Near-mature forest }\end{array}$ & $\begin{array}{c}\text { 成熟林 } \\
\text { Mature forest }\end{array}$ & $\begin{array}{c}\text { 过熟林 } \\
\text { Over-mature forest }\end{array}$ \\
\hline 云杉林 Picea forest & $\leqslant 60$ & $61-100$ & $101-120$ & $121-160$ & $\geqslant 161$ \\
柏木林 Cupressus funebris forest & $\leqslant 60$ & $6-100$ & $101-120$ & $121-160$ & $\geqslant 161$ \\
桦木林 Betula forest & $\leqslant 30$ & $31-50$ & $51-60$ & $61-80$ & $\geqslant 81$ \\
杨树林 Populus forest & $\leqslant 10$ & $11-15$ & $16-20$ & $21-30$ & $\geqslant 31$ \\
\hline
\end{tabular}

引用自关晋宏等(2016)。

Based on Guan et al. (2016).

1.4.1.2 青海省乔木层及主要林型固碳现状的估算 根据现有的不同龄级林型的碳密度, 结合青海省森 林资源连续清查第五次复查结果(2008年)所提供的 相对应的林地面积, 估算出青海省2011年乔木层植 被总碳储量 $\left(C_{\mathrm{F}}, \mathrm{Tg}\right)$ (王建等, 2016)。

$$
C_{F}=\sum_{i=1}^{j} \sum_{j=1}^{j}\left(C_{F j, i} \times A_{F j, i}\right) / 1000000
$$

式中, $C_{F j, i}$ 为第种林型第 $j$ 个林龄的森林生态系统碳
密度 $\left(\mathrm{Mg} \cdot \mathrm{hm}^{-2}\right) ; A_{F j, i}$ 为第 $i$ 种林型第 $j$ 个林龄的分布面 积 $\left(\mathrm{hm}^{2}\right)$ 。

\subsection{2 青海省乔木层总固碳速率及主要林型固碳} 速率的估算

根据现有样地调查估算出的碳储量各项数据, 结合两次青海省森林资源连续清查资料(2003年、 2008年), 估算出的2003年各林型碳储量以及总碳 储量，进而算出该年各林型碳密度以及总碳密度。

www.plant-ecology.com 
通过不同时期乔木层植被碳密度变化量来估算青海 省乔木层的总体固碳速率 $\left(\Delta C_{\mathrm{F}}, \mathrm{Mg} \cdot \mathrm{hm}^{-2} \cdot \mathrm{a}^{-1}\right)$ 。并对 云杉林、柏木林、桦木林和杨树林的固碳速率分别 进行估算。

$$
\Delta C_{F}=\frac{\left(C_{F t 2}-C_{F t 1}\right)}{\left(t_{2}-t_{1}\right)}
$$

式中 $C_{F t 1} 、 C_{F t 2}$ 分别为 $t_{1} 、 t_{2}$ 时间的碳密度 $\left(\mathrm{Mg} \cdot \mathrm{hm}^{-2}\right)$ 。

\subsection{3 青海省乔木层及主要林型固碳潜力的估算}

固碳潜力通过理论最大固碳潜力和相对固碳潜 力 $\left(\mathrm{Mg} \cdot \mathrm{hm}^{-2}\right)$ 来表示。本研究估算的固碳潜力为天然 林理论最大固碳潜力, 假定森林面积不变的前提下, 根据森林演替理论把各林型成熟林碳密度的平均值 作为该林型演替终点的碳密度, 并作为该林型理论 最大固碳潜力的参照系来估算单位面积固碳潜力 (Sleutel et al., 2003)。

单位面积固碳潜力 $=$ 演替终点碳密度 平均碳密度

固碳潜力 $(\mathrm{Tg})$ 由单位面积固碳潜力 $\left(\mathrm{Mg} \cdot \mathrm{hm}^{-2}\right)$ 与该 林型占地面积 $\left(\mathrm{hm}^{2}\right)$ 相结合计算得出。

\section{2 结果和分析}

\section{1 青海省优势树种碳储量特征}

\subsection{1 不同林型固碳现状}

2011年青海省乔木总碳储量为 $27.38 \mathrm{Tg}$, 青海 省森林生态系统乔木层平均碳密度为 $76.54 \mathrm{Mg} \cdot \mathrm{hm}^{-2}$ 。 其中四大林型云杉林、柏木林、桦木林和杨树林占 森林总面积的 $96.23 \%$, 该四个林型的总固碳量占 $86.67 \%$; 其中云杉林的碳储量最高达到了 $14.78 \mathrm{Tg}$, 占青海省乔木植被碳储量的 $53.99 \%$; 柏木林总的碳 储量达到了 $5.29 \mathrm{Tg}$, 占青海省乔木植被碳储量的 19.34\%; 桦木林的碳储量达到了 $2.63 \mathrm{Tg}$, 占青海省 乔木植被碳储量的 $9.63 \%$; 杨树林的碳储量在四个 林型中最小, 为 $0.40 \mathrm{Tg}$, 占青海省乔木植被碳储量
的 $0.09 \%$ 。

通过计算各林型不同龄级样地碳密度, 对不同 龄级下的同一林型的碳密度取平均值, 得到各林型 的平均碳密度, 其中云杉林的碳密度最大, 为 $106.93 \mathrm{Mg} \cdot \mathrm{hm}^{-2}$; 其次是桦木林, 为 $43.55 \mathrm{Mg} \cdot \mathrm{hm}^{-2}$; 柏木林总固碳量大但其碳密度却相对较低, 为 38.31 $\mathrm{Mg} \cdot \mathrm{hm}^{-2}$; 杨树林碳密度最低, 为 $34.76 \mathrm{Mg} \cdot \mathrm{hm}^{-2}$ 。

\subsection{2 不同龄级乔木层固碳现状}

青海省幼龄林面积为 $6.43 \times 10^{4} \mathrm{hm}^{2}$; 中龄林面 积为 $12.35 \times 10^{4} \mathrm{hm}^{2}$; 近熟林面积 $5.28 \times 10^{4} \mathrm{hm}^{2}$; 成 熟林面积 $6.84 \times 10^{4} \mathrm{hm}^{2}$; 过熟林面积 $4.88 \times 10^{4} \mathrm{hm}^{2}$, 不同龄级的乔木碳储量、占地面积和蓄积量占总量 比例如图2所示。

过熟林碳储量 $(7.60 \mathrm{Tg})$ 为最高, 占总碳储量的 $27.76 \%$; 其次是中龄林 $(7.35 \mathrm{Tg})$, 占总碳储量的 $26.87 \%$; 第三位是成熟林 $(6.41 \mathrm{Tg})$, 占总碳储量的 $23.42 \%$; 近熟林 $(3.87 \mathrm{Tg}$ ) 和幼龄林 $(2.13 \mathrm{Tg}$ )碳储量 相对较小, 分别占总碳储量的 $14.16 \%$ 和 $7.77 \%$ 。幼龄 林、中龄林、近熟林、成熟林和过熟林碳密度介于 $5.76-62.62 、 24.57-85.52 、 46.91-87.78 、 62.28-108.93$ 和55.39-218.66 Mg.hm解之间(图3)。乔木林随着龄 级的上升, 碳密度呈现不断上升的趋势。

\section{2 青海省乔木层植被固碳速率}

根据2003年青海省森林资源清查资料求得, 2003 年青海省乔木层碳储量为 $23.26 \mathrm{Tg}$ 。即20032011 年青海省乔木层的平均年固碳速率为 1.06 $\mathrm{Mg} \cdot \mathrm{hm}^{-2} \cdot \mathrm{a}^{-1}$ 。2003年青海省云杉林碳储量为 14.10 $\mathrm{Tg}$; 柏木林为 $4.50 \mathrm{Tg}$; 桦木林为 $2.9 \mathrm{Tg}$; 杨树林为 $0.33 \mathrm{Tg}$ 。经计算云杉林固碳速率为 $0.34 \mathrm{Mg} \cdot \mathrm{hm}^{-2} \cdot \mathrm{a}^{-1}$; 柏木林固碳速率为 $0.44 \mathrm{Mg} \cdot \mathrm{hm}^{-2} \cdot \mathrm{a}^{-1}$; 桦木林固碳速 率为 $-1.06 \mathrm{Mg} \cdot \mathrm{hm}^{-2} \cdot \mathrm{a}^{-1}$; 杨树林固碳速率为 0.27 $\mathrm{Mg} \cdot \mathrm{hm}^{-2} \cdot \mathrm{a}^{-1}$ 。在2003-2011年这 8 年中柏木林固碳速 率最高, 其中仅桦木林的固碳速率为负值。

表3 青海省不同林型占地面积、碳密度和碳储量

Table 3 The area, carbon density and storage of different forest types in Qinghai Province

\begin{tabular}{|c|c|c|c|}
\hline 林型 Forest type & 平均碳密度 Carbon density $\left(\mathrm{Mg} \cdot \mathrm{hm}^{-2}\right)$ & 面积 Area $\left(\times 10^{4} \mathrm{hm}^{2}\right)$ & 碳储量 Carbon storage ( $\mathrm{Tg}$ ) \\
\hline 云杉林 Picea forest & 106.93 & 10.38 & 14.78 \\
\hline 柏木林 Cupressus funebris forest & 38.31 & 13.83 & 5.29 \\
\hline 桦树林 Betula forest & 43.55 & 6.06 & 2.63 \\
\hline 杨树林 Populus forest & 34.76 & 4.16 & 0.40 \\
\hline
\end{tabular}

引自青海省森林资源连续清查资料第五次复查成果(2008年)。

Based on the fifth resources inventory of Qinghai forest (2008). 


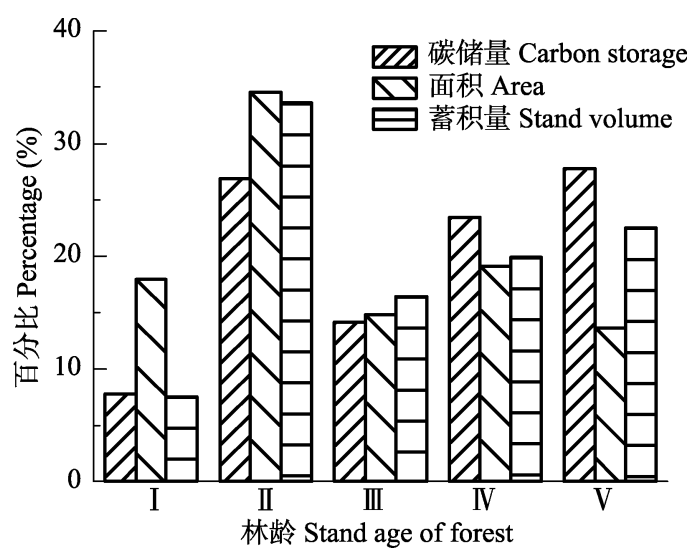

图2 不同龄级乔木碳储量、面积和蓄积量占总量的比例。 I, 幼龄林; II, 中龄林; III, 近熟林; IV, 成熟林; V, 过熟林。 Fig. 2 The frequency distribution of carbon storage, area and accumulation among different forest age classes. I, young forest; II, middle-aged forest; III, near-mature forest; IV, mature forest; $\mathrm{V}$, over-mature forest.

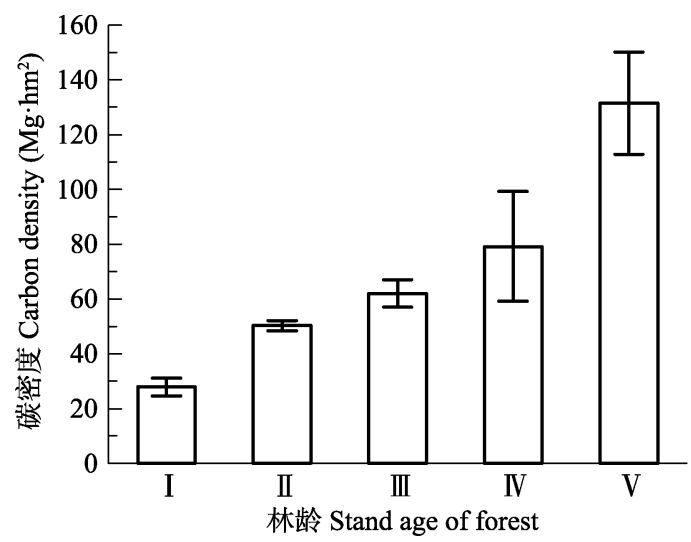

图3 青海省不同林龄森林碳密度(平均值土标准偏差)。I, 幼 龄林; II, 中龄林; III, 近熟林; IV, 成熟林; V, 过熟林。

Fig. 3 Carbon density of tree layer among different forest age classes in Qinghai Province (mean $\pm S D$ ). I, young forest; II, middle-aged forest; III, near-mature forest; IV, mature forest; V, over-mature forest.

表4 2003-2011年青海省乔木林平均年固碳量和固碳速率

Table 4 Mean annual carbon sequestration and carbon sequestration rate of forest arbor from 2003 to 2011 in Qinghai Province

\begin{tabular}{|c|c|c|c|c|}
\hline \multirow[t]{2}{*}{$\begin{array}{l}\text { 林型 } \\
\text { Forest type }\end{array}$} & \multicolumn{2}{|c|}{$\begin{array}{c}\text { 碳储量 } \\
\text { Carbon storage (Tg) }\end{array}$} & \multirow{2}{*}{$\begin{array}{c}\text { 固碳速率 } \\
\text { Carbon sequestration } \\
\text { rate }\left(\mathrm{Mg} \cdot \mathrm{hm}^{-2} \cdot \mathrm{a}^{-1}\right)\end{array}$} & \multirow{2}{*}{$\begin{array}{c}\text { 年均碳增量 } \\
\text { Average annual growth } \\
\text { of carbon }\left(\mathrm{Tg} \cdot \mathrm{a}^{-1}\right)\end{array}$} \\
\hline & 2003 & 2011 & & \\
\hline 云杉林 Picea forest & 14.00 & 14.78 & 0.34 & 0.09 \\
\hline 柏木林 Cupressus funebris forest & 3.00 & 5.29 & 0.44 & 0.10 \\
\hline 桦树林 Betula forest & 4.50 & 2.63 & -1.06 & -0.04 \\
\hline 杨树林 Populus forest & 0.30 & 0.40 & 0.27 & 0.01 \\
\hline
\end{tabular}

引自青海省森林资源连续清查第四次复查成果资料(2003年)。

Based on the fifth resources inventory of Qinghai forest (2003).

\section{3 青海省乔木层植被固碳潜力}

2011年青海省乔木植被单位面积固碳潜力为 $23.77 \mathrm{Mg} \cdot \mathrm{hm}^{-2}$, 总固碳潜力为 $8.50 \mathrm{Tg}$ 。各林型单位 面积固碳潜力和总固碳潜力分别为: 云杉林 $(32.80$ $\left.\mathrm{Mg} \cdot \mathrm{hm}^{-2}, 3.40 \mathrm{Tg}\right)>$ 柏木林 $\left(22.26 \mathrm{Mg} \cdot \mathrm{hm}^{-2}, 2.97 \mathrm{Tg}\right)$ $>$ 白桦林 $\left(19.58 \mathrm{Mg} \cdot \mathrm{hm}^{-2}, 1.19 \mathrm{Tg}\right)>$ 杨树林 $(0.97$ $\left.\mathrm{Mg} \cdot \mathrm{hm}^{-2}, 0.04 \mathrm{Tg}\right)($ 图4)。

\section{3 讨论}

\section{1 青海省森林乔木在全国森林生态系统碳汇中 的地位}

青海省地处青藏高原东北部, 由于气候、地形 影响境内林木稀少，森林覆盖率仅为 $4.57 \%$, 仅略 高于新疆(4.24\%，郭远平, 2015)。Tang等(2018)估测 我国森林植被碳储量为12.67-13.47 Pg, 根据本次 实地调查数据估测得到的乔木层碳储量为 $27.38 \mathrm{Tg}$, 青海省乔木碳储量占全国碳储量的 $0.20 \%-0.22 \%$ 。 但由于其特殊的地理位置, 所带来的生态效益极大,

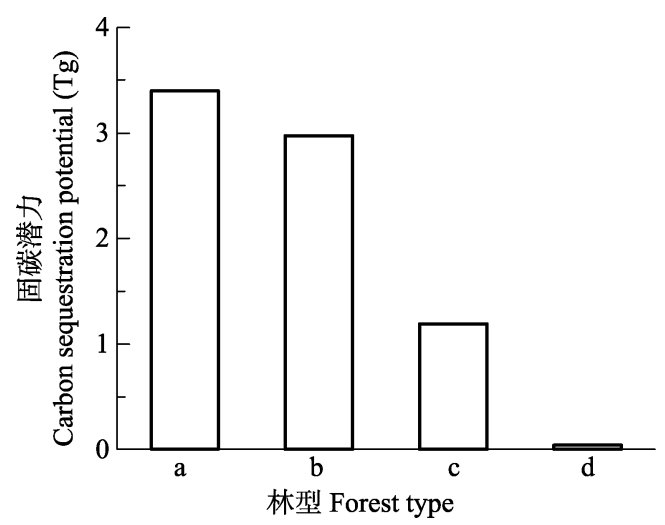

图4 不同林型固碳潜力。 $\mathrm{a}$ ，云杉林； b，柏木林； c，桦木林； d, 杨树林。

Fig. 4 Carbon sequestration potential of different forest types. a, Picea forest; b, Sabina chinensis forest; c, Betula forest; d, Populus forest.

因而该地区的森林生态系统虽然碳汇功能相对其他 省份较弱, 但其生态功能不可忽视。

青海省乔木层碳密度为76.54 $\mathrm{Mg} \cdot \mathrm{hm}^{-2}$, 高于 方精云等 (2007)(41.0 $\left.\mathrm{Mg} \cdot \mathrm{hm}^{-2}\right)$ 和 Tang 等 (2018) www.plant-ecology.com 
$\left(42.5 \mathrm{Mg} \cdot \mathrm{hm}^{-2}\right)$ 估算的全国森林生态系统乔木层平 均碳密度, 同时也高于毗邻的甘肃省(69.10 Mg $\mathrm{hm}^{-2}$, 关晋宏等, 2016)和四川省 $\left(41.66 \mathrm{Mg} \cdot \mathrm{hm}^{-2}\right.$, 黄从德 等, 2008)。究其原因, 首先青海省分布有大量的云 杉、圆柏等寒温性针叶林, 其碳储量和面积合计分 别占全省森林的 $73.33 \%$ 和 $67.66 \%$, 且针叶林平均碳 密度(136.59 $\left.\mathrm{Mg} \cdot \mathrm{hm}^{-2}\right)$ 要远高于阔叶林平均碳密度 $\left(38.92 \mathrm{Mg} \cdot \mathrm{hm}^{-2}\right)$; 其次在本次实地调查过程中发现 青海省过熟林较多, 且青海省过熟林碳密度普遍高 于成熟林, 在选取的 240 个采样点中 69 个采样点为 过熟林, 占总采样点数的 $28.75 \%$ 。

青海省2003年至2011年8年内平均年固碳速率 为 $1.06 \mathrm{Mg} \cdot \mathrm{hm}^{-2} \cdot \mathrm{a}^{-1}$, 高于青藏高原高寒区阔叶林固 碳速率(2001-2006年, $0.19 \mathrm{Mg} \cdot \mathrm{hm}^{-2} \cdot \mathrm{a}^{-1}$, 王建等, 2016), 同时也高于甘肃省 (1996-2011 年，0.91 $\mathrm{Mg} \cdot \mathrm{hm}^{-2} \cdot \mathrm{a}^{-1}$, 关晋宏等, 2016), 但略低于四川省(含 重庆地区) 的固碳速率 (1999-2003 年, 1.10 $\mathrm{Mg} \cdot \mathrm{hm}^{-2} \cdot \mathrm{a}^{-1}$, 黄从德等, 2008)。一方面因为青海省 幼龄林和中龄林占地面积比例 $52.49 \%$, 超过了全省 森林生态系统占地面积的 50\%, 另一方面青海省 2003-2011年间森林面积增加了 1.59 万 $\mathrm{hm}^{2}$ 。这两点 是促使青海省乔木层固碳速率较大的主要原因。固 碳潜力方面青海省森林生态系统乔木层单位面积固 碳潜力为 $23.77 \mathrm{Mg} \cdot \mathrm{hm}^{-2}$, 高于青藏高原高寒区阔叶 林单位面积固碳潜力 $\left(19.09 \mathrm{Mg} \cdot \mathrm{hm}^{-2}\right.$, 王建等, 2016)。未来, 随着大量低龄林逐渐发展为成熟林, 将对青海省森林生态系统碳储量做出重要贡献。

\section{2 青海省森林乔木层碳储量和碳密度影响因素}

青海省为典型的高原大陆性气候, 但降水在省 内分布极不均匀, 各地区温度也存在较大差异, 而 降水和气温是影响生态系统碳储量和碳密度分布的 关键(吕超群和孙书存, 2004; 黄从德等, 2009)。本次 研究的森林生态系统基本分布在青海省东部和南部 部分地区, 调查区生长季平均气温在 $10-14{ }^{\circ} \mathrm{C}$ 范围 内, 地表温度在 $12-20{ }^{\circ} \mathrm{C}$ 范围内, 累积降水均高于 $160 \mathrm{~mm}$ 。而没有形成森林生态系统的玉树西部、柴 达木盆地及周边等地区生长季地表温度均高于 $20{ }^{\circ} \mathrm{C}$, 且累积降水量均低于 $160 \mathrm{~mm}$ (刘雪梅等, 2017)。因此受生长季地表温度和累积降水量的影响, 青海省森林生态系统的形成区域受限, 影响了青海 省森林乔木层的碳储量。

坡度主要影响树冠层所接受的光照以及土壤水
肥状况，因而与乔木层碳密度显著相关(沈彪等, 2015; 王琰等, 2015)。结合实地测量信息和坡度划 分标准(黄从德等, 2009), 我们将坡度分为平坡 $\left(0-5^{\circ}, 30\right.$ 个 $)$ 、缓坡 $\left(6^{\circ}-15^{\circ}, 66\right.$ 个 $)$ 、斜坡 $\left(16^{\circ}-25^{\circ}, 60\right.$ 个)、陡坡 $\left(26^{\circ}-35^{\circ}, 35\right.$ 个 $) 、$ 急坡 $\left(36^{\circ}-45^{\circ}, 26\right.$ 个 $)$ 和险 坡 $\left(\geqslant 46^{\circ}, 23\right.$ 个)。其中平坡平均碳密度为 68.61 $\mathrm{Mg} \cdot \mathrm{hm}^{-2}$; 缓坡平均碳密度为 $63.64 \mathrm{Mg} \cdot \mathrm{hm}^{-2}$; 斜坡 平均碳密度为 $46.10 \mathrm{Mg} \cdot \mathrm{hm}^{-2}$; 陡坡平均碳密度为 $47.43 \mathrm{Mg} \cdot \mathrm{hm}^{-2}$; 急坡平均碳密度为 $88.86 \mathrm{Mg} \cdot \mathrm{hm}^{-2}$; 险坡平均碳密度为 $102.59 \mathrm{Mg} \cdot \mathrm{hm}^{-2}$ 。可以看出随着 坡度变化, 乔木层碳密度呈现先下降后上升的趋 势。这与已有研究得到的随着坡度增大碳密度随之 上升(王琰等, 2015)或先上升后下降的结果(黄从德 等, 2009; 沈彪等, 2015)存在差异。造成这种现象的 原因是在急坡、险坡区域虽然其水分、调落物等积 累量较少, 但是因其地形影响不利于人工利用, 导 致了在该坡度下过熟林样方占比较高(61.22\%), 进 而导致其平均碳密度明显高于其他坡度; 平坡、缓 坡、斜坡和陡坡这四个坡度均会受到人为扰动影响， 而平坡、缓坡区域的养分积累条件要优于斜坡、陡 坡区域，所以其碳密度相对高于斜坡、陡坡区域。

海拔因素对碳密度也存在影响(沈彪等, 2015; 王琰等, 2015), 本次实地调查中选取的样地海拔在 2 175-3 $852 \mathrm{~m}$ 之间, 将其划分为: 2000-2 $500 \mathrm{~m}$ (25 个)、2 500-3000 m (129个)、3000-3 500 m (35个) 和3 500-4000 m (51个) 4个海拔梯度, 这4个海拔梯 度内样方的平均碳密度分别为: 58.38、55.32、94.64 和68.00 Mg $\cdot \mathrm{hm}^{-2}$ 。随着海拔的升高碳密度呈现先上 升后下降的趋势。这与其他研究得到的结论(沈彪等, 2015; 王琰等, 2015)相似，海拔3 $000 \mathrm{~m}$ 以上地区的 乔木所受到的人为扰动较小, 所以其平均碳密度高 于海拔3 $000 \mathrm{~m}$ 以下区域; 3 500-4000 m海拔梯度上 因水分、温度的限制相对不适宜乔木生长, 所以其 平均碳密度低于3 000-3 $500 \mathrm{~m}$ 区域。同时通过本次 实地调查也发现在海拔 $3000 \mathrm{~m}$ 以上, 不存在阔叶 类树种为优势种的样地类型, 针叶类乔木喜温凉气 候且抗寒能力较强, 因而针叶类乔木在不同海拔梯 度区域都有作为优势种存在的现象。以针叶林为优 势树种的调查样地平均碳密度为 $136.59 \mathrm{Mg} \cdot \mathrm{hm}^{-2}$, 阔叶林为优势种的样地平均碳密度仅为 38.92 $\mathrm{Mg} \cdot \mathrm{hm}^{-2}$ 。因此, 人为扰动和林型差异导致了在海拔 $3000 \mathrm{~m}$ 以下地区的平均碳密度低于海拔 $3000 \mathrm{~m}$ 以 
上的地区。

\section{3 估算结果的不确定性}

不同估算方法的差异导致了碳储量估算的结果 差异较大。胡雷等(2015)、卢航等(2013)依据青海省 森林清查资料结合生物量与蓄积量回归方程估算的 青海省2008年总碳储量为 $11.18 \mathrm{Tg}$, 本研究中得到 的青海省2011年乔木层碳储量 $27.38 \mathrm{Tg}$ 结果与之存 在差异。生物量与蓄积量回归方程中主要影响碳储 量的因素为蓄积量、回归方程的拟合性和各林型面 积值的选取, 影响本研究所得到的碳储量的主要因 素为各林型不同龄级下的平均碳密度和各林型面积 的取值。因本研究与上述两项研究选取的各林型面 积均为2008年青海省森林资源清查资料所提供, 共 计 $35.78 \times 10^{4} \mathrm{hm}^{2}$, 故结果的差异主要来自于依据 生物量与蓄积量回归方程所得到的碳密度与实地测 量所得到的碳密度值的差异。以云杉林为例, 卢航 等(2013)估算得到的2008年青海省云杉碳密度为 $28.33 \mathrm{Mg} \cdot \mathrm{hm}^{-2}$, 本研究调查样方内纯云杉(采用 240 个样方内全部云杉的碳储量除以有云杉生长样方的 总面积求得)的碳密度为 $47.04 \mathrm{Mg} \cdot \mathrm{hm}^{-2}$ 。造成碳密度 差异的原因首先是通过生物量与蓄积量回归方程与 异速生长方程计算乔木生物量方法的不同所造成的 差异, 生物量的计算结果将直接影响碳储量的计算, 本研究结果表明针对青海省森林乔木两种生物量估 算方法所得到结果差异较大; 其次是样方法存在的 缺陷, 因地形和样方具体选取范围等因素的影响, 即便通过大范围、多位点标准的进行样方设置, 但 也还不能做到完全代表青海省森林生态系统; 第三 是含碳率的取值, 卢航等(2013)选取的含碳率为普 遍的 $50 \%$, 本研究通过对标准木各个器官含碳率的 分别测定，得到全株云杉的含碳率约为 $47.22 \%$ 。另 外, 在调查样地中多以天然林为主, 所以样地内树 种多样性较高, 对优势种的判定难度较高。本文中 样地龄级是依据优势树种龄级来判定的, 低龄级样 方中也存在高龄级非优势种乔木生长的现象, 这也 一定程度地导致了有些低龄级的样地存在碳密度较 高的情况。本研究并未考虑2008年至2011年3年间森 林面积的变化量, 从2003年至2008年青海省森林面 积由 $34.19 \times 10^{4} \mathrm{hm}^{2}$ 增加至 $35.78 \times 10^{4} \mathrm{hm}^{2}$, 故森林 面积取值也是本次青海省森林乔木总碳储量估算的 不确定因素。

\section{4 结论}

本研究根据实地调查数据结合青海省森林资源 连续清查资料，估算出了青海省森林生态系统乔木 层的总碳储量、碳密度、固碳速率和固碳潜力。青 海省乔木层碳储量和碳密度分别为 $27.38 \mathrm{Tg}$ 和 76.54 $\mathrm{Mg} \cdot \mathrm{hm}^{-2}$ 。碳储量相较于其他省份较低, 但碳密度处 于一个相对较高的水平上。其中针叶林的碳储量和 碳密度均高于阔叶林。随着森林保护工程和生态文 明建设的开展，青海省森林面积不断增加，年固碳 量稳定上升; 同时较高的中、幼龄林比例也保证了 青海省固碳潜力相对较高。因此，通过坚持合理利 用森林资源，杜绝乱砍滥伐，充分发挥其对三江源 区涵养水源、调节气候、防风固沙的作用，同时保 障青海省乃至整个西部地区生态环境的稳定发展, 丰富区域内的各类生态资源。

致谢感谢西南民族大学研究生创新项目 (CX2018SZ103)资助。

\section{参考文献}

Akselsson C, Berg B, Meentemeyer V, Westling O (2005). Carbon sequestration rates in organic layers of boreal and temperate forest soils-Sweden as a case study. Global Ecology and Biogeography, 14, 77-84.

Chen WN, Wu N, Luo P, Yan ZL (2003). Species diversity and arbor population distribution pattern of Sabina przewalskll community in the forest-grassland ecotone in the watershed of upper Minjiang River. Chinese Journal of Applied Environmental Biology, 9，221-225. [陈文年，吴宁，罗 鹏, 晏兆莉 (2003). 岷江上游林草交错带祁连山圆柏群 落的物种多样性及乔木种群的分布格局. 应用与环境 生物学报, 9, 221-225.]

Dixon RK, Solomon AM, Browm S, Houghton RA, Trexier MC, Wisniewski J (1994). Carbon pools and fluxes of global forest ecosystems. Science, 263, 185-190.

Dong M (1997). Survey, Observation and Analysis of Terrestrial Biocenosis. Standards Press of China, Beijing. [董鸣 (1997). 陆地生物群落调查观测与分析. 中国标准出版 社, 北京.]

Dong X (2009). Evaluation of forest resources in Qinghai Province. Journal of Anhui Agricultural Sciences, 37, 5727-5728. [董旭 (2009). 青海省森林资源评价. 安徽 农业科学, 37, 5727-5728.]

Fang J, Chen A, Peng C, Zhao S, Ci L (2001). Changes in forest biomass carbon storage in China between 1949 and 1998. Science, 292, 2320-2322.

Fang JY, Guo ZD (2007). Looking for missing carbon sinks 
from terrestrial ecosystems. Chinese Journal of Nature, 29，1-6. [方精云, 郭兆迪 (2007). 寻找失去的陆地碳 汇. 自然杂志, 29, 1-6.]

Fang JY, Guo ZD, Piao SL, Chen AP (2007). Estimation of carbon sink in China land from 1981 to 2000. Scientia Sinica (Terrae), 37, 804-812. [方精云, 郭兆迪, 朴世龙, 陈安平 (2007). 1981-2000年中国陆地植被碳汇的估算. 中国科学: 地球科学, 37, 804-812.]

Fang JY, Xu SL (1996). Biomass and net production of forest vegetation in China. Acta Ecologica Sinica, 16, 497-508. [方精云, 徐嵩龄 (1996). 我国森林植被的生物量和净 生产量. 生态学报, 16, 497-508.]

Guan JH, Du S, Cheng JM, Wu CR, Li GQ, Deng L, Zhang JG, He QY, Shi WY (2016). Current stocks and rate of sequestration of forest carbon in Gansu Province, China. Chinese Journal of Plant Ecology, 40, 304-317. [关晋宏, 杜盛, 程积民, 吴春荣, 李国庆, 邓否, 张建国, 何秋 月, 时伟宇 (2016). 甘肃省森林碳储量现状与固碳速 率. 植物生态学报, 40, 304-317.]

Guo YP (2015). Thinking on the sustainable management of forest resources in Xinjiang. Forestry of Xinjiang, (1), 18-20. [ 郭远平 (2015). 关于新疆森林资源可持续经营 的思考. 新疆林业, (1), 18-20.]

Hu L, Wang CT, Wang GX, Liu W, ADe LJ (2015). Carbon sequestration of forest ecosystem vegetation in Qinghai Province. Southwest China Journal of Agricultural Sciences, 28, 826-832. [胡雷, 王长庭, 王根绪, 刘伟, 阿的 鲁䩀 (2015). 青海省森林生态系统植被固碳现状研究. 西南农业学报, 28, 826-832.]

Huang CD, Zhang J, Yang WQ, Tang X, Zhang GQ (2009). Spatial differentiation characteristics of forest vegetation carbon stock in Sichuan Province. Acta Ecologica Sinica, 29, 5115-5121. [黄从德, 张健, 杨万勤, 唐宵, 张国庆 (2009). 四川省森林植被碳储量的空间分异特征. 生态 学报, 29, 5115-5121.]

Huang CD, Zhang J, Yang WQ, Tang X, Zhao AJ (2008). Dynamics on forest carbon stock in Sichuan Province and Chongqing City. Acta Ecologica Sinica, 28, 966-975. [黄 从德, 张健, 杨万勤, 唐宵, 赵安玖 (2008). 四川省及 重庆地区森林植被碳储量动态。生态学报, 28 , 966-975.]

Huang XQ, Xin CL, Hu ZM, Li GT, Zhang TH, Zhao W, Yang H, Zhang LM, Guo Q, Yue YJ, Gao RH, Wu ZY, Yan ZG, Liu XP, Li YQ, Li SG (2016). Carbon storage of the forests and its spatial pattern in Nei Mongol, China. Chinese Journal of Plant Ecology, 40, 327-340. [黄晓琼, 辛存林, 胡中民, 李钢铁, 张铜会, 赵玮, 杨浩, 张雷明, 郭群, 岳永杰, 高润红, 乌志颜, 问志刚, 刘新平, 李玉强, 李 胜功 (2016). 内蒙古森林生态系统碳储量及其空间分 布. 植物生态学报, 40, 327-340.]

Kauppi PE, Mielikäinen K, Kuusela K (1992). Biomass and carbon budget of European forests, 1971 to 1990. Science, 256, 70-74.

LI KR, Wang SQ, Cao MK (2004). Vegetation and soil carbon storage in China. Science in China, 47, 49-57.
Li Y, Chen GL, Lin DM, Chen B, Gao LM, Jian X (2016). Carbon storage and its distribution of forest ecosystems in Zhejiang Province, China. Chinese Journal of Plant Ecology, 40, 354-363. [李银, 陈国科, 林敦梅, 陈涁, 高雷 明, 简兴 (2016). 浙江省森林生态系统碳储量及其分布 特征. 植物生态学报, 40, 354-363.]

Liu GH, Fu BJ, Fang JY (2000). Carbon dynamics of Chinese forests and its contribution to global carbon balance. Acta Ecologica Sinic，20，733-740. [刘国华，傅伯杰，方精云 (2000). 中国森林碳动态及其对全球碳平衡的贡献. 生 态学报, 20, 733-740.]

Liu XM, Gao XH, Ma YC (2017). Spatio-temporal evolution of vegetation coverage in Qinghai Province, China during the periods from 2002 to 2015. Arid Zone Research, 34, 1345-1352. [ 刘雪梅, 高小红, 马元仓 (2017). 2002-2015年青海省不同气候区植被覆盖时空变化. 干 旱区研究, 34, 1345-1352.]

Lü CQ, Sun SC (2004). A review on the distribution patterns of carbon density in terrestrial ecosystems. Acta Phytoecologica Sinica，28，692-703. [吕超群，孙书存 (2004). 陆地生态系统碳密度格局研究概述. 植物生态 学报, 28, 692-703.]

Lu H, Liu K, Wu JH (2013). Change of carbon storage in forest vegetation and current situation analysis of Qinghai Province in recent 20 years. Resources and Environment in the Yangtze Basin，22，1333-1338. [卢航，刘康，吴金鸿 (2013). 青海省近20年森林植被碳储量变化及其现状分 析. 长江流域资源与环境, 22, 1333-1338.]

Luan JW, Liu SR, Zhu XL, Wang JX (2011). Soil carbon stocks and fluxes in a warm-temperate oak chronosequence in China. Plant and Soil, 347, 243-253.

Luo TX, Li W, Zhu H, Leng YF, Yue YZ (1998). Estimation of total biomass and potential distribution of net primary productivity in the Tibetan Plateau. Geographical Research, 17, 337-344. [罗天祥, 李文华, 冷允法, 岳燕珍 (1998). 青藏高原自然植被总生物量的估算与净初级生 产量的潜在分布. 地理研究, 17, 337-344.]

Pan Y, Birdsey RA, Fang J, Houghton R, Kauppi PE, Kurz WA, Phillips OL, Shvidenko A, Lewis SL, Canadell JG, Ciais P, Jackson RB, Pacala SW, McGuire AD, Piao S, Rautiainen A, Sitch S, Hayes D (2011). A large and persistent carbon sink in the world's forests. Science, 333, 988-993.

Pan Y, Birdsey RA, Phillips OL, Jackson RB (2013). The structure, distribution, and biomass of the world's forests. Annual Review of Ecology, Evolution, and Systematics, 44, 593-622.

Rice AH, Pyle EH, Saleska SR, Hutyra L, Palace M, Keller M, Camargo PB, Portilho K, Marques DF, Wofsy SC (2004). Carbon balance and vegetation dynamics in an old-growth Amazonian forest. Ecological Applications, 14, S55-S71.

Schlesinger WH (1977). Carbon balance in terrestrial detritus. Annual Review of Ecology and Systematics, 8, 51-81.

Shen B, Dang KL, Wu PH, Zhu CG (2015). Organic carbon density in Pinus tabulaeformis forest ecosystem on the 
south slope of the middle Qinling Mountains, China. Acta Ecologica Sinica, 35, 1798-1806. [沈彪, 党坤良, 武朋 辉, 朱成功 (2015). 秦岭中段南坡油松林生态系统碳密 度. 生态学报, 35, 1798-1806.]

Sleutel S, de Neve S, Hofman G, Boeckx P, Beheydt D, van Cleemput O, Mestdagh I, Lootens P, Carlier L, van Camp N, Verbeeck H, Vande Walle I, Samson R, Lust N, Le-meur R (2003). Carbon stock changes and carbon seques-tration potential of flemish cropland soils. Global Change Biology, 9, 1193-1203.

Sun SQ, Wang SH, Chen YQ, Zou T (2008). The research on carbon fixation of high wood in Anhui. Environmental Science and Management, 33, 144-147. [孙世群, 王书航, 陈月庆, 邹婷. (2008). 安徽省乔木林固碳能力研究. 环 境科学与管理, 33, 144-147.]

Tang X, Zhao X, Bai Y, Tang Z, Wang W, Zhao Y, Wan H, Xie Z, Shi X, Wu B, Wang G, Yan J, Ma K, Du S, Li S, Han S, Ma Y, Hu H, He N, Yang Y, Han W, He H, Yu G, Fang J, Zhou G (2018). Carbon pools in China's terrestrial ecosystems: New estimates based on an intensive field survey. Proceedings of the National Academy of Sciences of the United States of America, 115, 4021-4026.

Tans PP, Thoning KW, Elliott WP, Conway TJ (1990). Error estimates of background atmospheric $\mathrm{CO}_{2}$, patterns from weekly flask samples. Journal of Geophysical Research Atmospheres, 95, 14063-14070.

Technical Manual Writing Group of Ecosystem Carbon Sequestration Project (2015). Observation and Investigation for Carbon Sequestration in Terrestrial Ecosystems. Science Press, Beijing. [生态系统固碳项目技术规范编写组 (2015). 生态系统固碳观测与调查技术规范. 科学出版 社, 北京.]

Wang J, Wang GX, Wang CT, Ran F, Chang RY (2016). Carbon storage and potentials of the broad-leaved forest in alpine region of the Qinghai-Xizang Plateau, China. Chinese Journal of Plant Ecology, 40, 374-384. [王建, 王根绪, 王长庭, 再飞, 常瑞英 (2016). 青藏高原高寒区阔叶林 植被固碳现状、速率和潜力. 植物生态学报, 40, 374-384.]

Wang XK, Bai YY, Ouyang ZY, Miao H (2002). Missing sink in global carbon cycle and its causes. Acta Ecologica Sinica，22，94-103. [王效科, 白艳荣, 欧阳志云, 苗鸿 (2002). 全球碳循环中的失汇及其形成原因. 生态学报, 22, 94-103.]

Wang XK, Feng ZW, Ouyang ZY (2001). Vegetation carbon storage and density of forest ecosystems in China. Chinese Journal of Applied Ecology, 12, 13-16. [王效科, 冯宗炜, 欧阳志云 (2001). 中国森林生态系统的植物碳储量和 碳密度研究. 应用生态学报, 12, 13-16.]
Wang XY, Sun YJ (2008). Review on research and estimation methods of carbon storage in forest ecosystem. World Forestry Research, 21(5), 24-29. [王秀云, 孙玉军 (2008). 森林生态系统碳储量估测方法及其研究进展. 世界林业研究, 21(5), 24-29.]

Wang Y, Wang MB, Zhu SZ, Zhao TL (2015). Carbon densities of major tree species in forests in southern Lüliang Mountains of Shanxi Province, China. Chinese Journal of Ecology, 34，333-340. [王琰, 王孟本, 朱世忠, 赵天梁 (2015). 山西吕梁山南段森林乔木层碳密度. 生态学杂 志, 34, 333-340.]

Wani AA, Joshi PK, Singh O, Bhat JA (2014). Estimating soil carbon storage and mitigation under temperate coniferous forests in the southern region of Kashmir Himalayas. Mitigation and Adaptation Strategies for Global Change, 19, 1179-1194.

Yang HX, Wu B, Zhang JT, Lin DR, Chang SL (2005). Progress of research into carbon fixation and storage of forest ecosystems. Journal of Beijing Normal University (Natural Science), 41，172-177. [杨洪晓, 吴波, 张金屯, 林德 荣, 常顺利 (2005). 森林生态系统的固碳功能和碳储量 研究进展. 北京师范大学学报, 自然科学版, 41, 172-177.]

Zhang P, Wang G, Zhang T, Chen NL (2010). Responses of foliar $\delta^{13} \mathrm{C}$ in Sabina przewalskii and Picea crassifolia to altitude and its mechanism in the Qilian Mountains, China. Chinese Journal of Plant Ecology, 34, 125-133. [张鹏, 王 刚, 张涛, 陈年来 (2010). 祁连山两种优势乔木叶片 $\delta^{13} \mathrm{C}$ 的海拔响应及其机理. 植物生态学报, 34, 125-133.]

Zhang WX, Zhou YD, Huang QL, Zhou YW, Mo LJ (2012). Advances in estimation of vegetation carbon stocks of forest ecosystem in China. Forest and Environmental Science, 28(4), 50-55. [张玮辛, 周永东, 黄倩琳, 周永文, 莫罗坚 (2012). 我国森林生态系统植被碳储量估算研 究进展. 林业与环境科学, 28(4), 50-55.]

Zhang YL, Yang FW, Lu SW (2007). Estimation on the economic values of the forest ecosystem service function in Qinghai Province. Journal of Northeast Forestry University, 35(11)，74-76. [张永利, 杨峰伟, 鲁绍伟 (2007). 青海省森林生态系统服务功能价值评估. 东北林业大 学学报, 35(11), 74-76.]

Zhao M, Zhou GS (2004). Carbon storage of forest vegetation and its relationship with climatic factors. Scientia Geographica Sinica, 24, 50-54. [赵敏, 周广胜 (2004). 中国森林生态系统的植物碳咜量及其影响因子分析. 地理科学, 24, 50-54.]

特邀编委: 李胜功 责任编辑: 李 敏 